\title{
Crescimento de mudas de pau-ferro sob diferentes níveis de sombreamento ${ }^{1}$
}

\author{
Nádia Regina Lenhard ${ }^{2}$, Vespasiano Borges de Paiva Neto ${ }^{3}$, \\ Silvana de Paula Quintão Scalon ${ }^{2}$, Amauri Alves de Alvarenga ${ }^{4}$
}

\begin{abstract}
Growth of Caesalpinia ferrea seedlings under different shading levels

Obtaining native seedlings requires information about seeds harvest time, storage and luminosity conditions, germination and types of substrate, among others. This study aimed at evaluating the luminosity demands for the initial growth of Caesalpinia ferrea Mart. ex. Tul. var. leiostachya Benth (Fabaceae-Caesalpinioideae) seedlings submitted to different shading levels, at 60 days after transplant (DAT). The experimental design was completely randomized, in $3 \times 5$ factorial scheme (three shading levels: $0 \%, 50 \%$ and $70 \%$; and five evaluation times: 60, 90, 120, 150 and 180 DAT), with four replications of 10 seedlings per experimental unit. Plants grown under the shading level of $70 \%$ presented the highest contents for total chlorophyll $\left(38.79 \mu \mathrm{g} \mathrm{cm}^{-2}\right)$, leaf area ratio $\left(51.54 \mathrm{~g} \mathrm{~cm}^{-2}\right)$, relative growth rate $\left(0.0322 \mathrm{~g} \mathrm{~g}^{-1}\right.$ day $\left.^{-1}\right)$ and leaf weight ratio $\left(0.2708 \mathrm{~g} \mathrm{~g}^{-1}\right)$. The highest values for stem height $(110.34 \mathrm{~cm})$ and base diameter $(9.3 \mathrm{~mm})$, and root $(11.13 \mathrm{~g})$, leaf $(5.59 \mathrm{~g})$ and shoot (16.05 g) dry matter, as well as leaf area $\left(705.25 \mathrm{~cm}^{2}\right)$, were observed in the plants cultivated under the shading level of $50 \%$. No differences were observed for root growth, specific leaf weight, net assimilation rate and specific leaf area, concerning the different shading levels tested (averages of $9.3 \mathrm{~cm}, 0.0082 \mathrm{~g} \mathrm{~cm}^{-2}, 0.0006 \mathrm{~g} \mathrm{~cm}^{-2}$ day $^{-1}$ and $186.24 \mathrm{~g} \mathrm{~cm}^{-2}$, respectively). The Caesalpinia ferrea seedlings presented a better growth rate when cultivated under the shading level of $50 \%$.
\end{abstract}

KEYS-WORDS: Caesalpinia ferrea Mart. ex. Tul. var. leiostachya Benth; plant ecophysiology; plant growth.

\section{INTRODUÇÃO}

A exploração florestal, no Brasil, continua apresentando caráter extrativista e predatório, gerando a degradação de áreas em quase todo o território nacional (Ferreira et al. 2000). A eliminação de complexos biomas pelas atividades agropecuárias

\section{RESUMO}

A obtenção de mudas nativas requer informações sobre a época de coleta das sementes, condições de armazenamento e luminosidade, germinação e tipos de substrato, dentre outras. Este trabalho objetivou avaliar as exigências de luminosidade no crescimento inicial de mudas de pau-ferro [Caesalpinia ferrea Mart. ex. Tul. var. leiostachya Benth (Fabaceae-Caesalpinioideae)] submetidas a diferentes níveis de sombreamento, aos 60 dias após o transplante (DAT). O delineamento experimental foi inteiramente casualizado, em esquema fatorial $3 \times 5$ (três níveis de sombreamento: $0 \%$, $50 \%$ e $70 \%$; e cinco épocas de avaliação: $60,90,120,150$ e 180 DAT), com quatro repetições de 10 mudas por unidade experimental. Plantas cultivadas sob $70 \%$ de sombreamento apresentaram maiores teores de clorofila total $\left(38,79 \mu \mathrm{g} \mathrm{cm}^{-2}\right)$, razão de área foliar $\left(51,54 \mathrm{~g} \mathrm{~cm}^{-2}\right)$, taxa de crescimento relativo $\left(0,0322 \mathrm{~g} \mathrm{~g}^{-1} \mathrm{dia}^{-1}\right)$ e razão de peso foliar $\left(0,2708 \mathrm{~g} \mathrm{~g}^{-1}\right)$. Os maiores valores para altura $(110,34 \mathrm{~cm})$, diâmetro $(9,3 \mathrm{~mm})$ e massa seca da raiz $(11,13 \mathrm{~g})$, da folha $(5,59 \mathrm{~g})$ e da parte aérea $(16,05 \mathrm{~g})$, bem como para área foliar $\left(705,25 \mathrm{~cm}^{2}\right)$, foram observados nas plantas cultivadas sob $50 \%$ de sombreamento. Não foram observadas diferenças quanto ao crescimento da raiz, peso específico foliar, taxa assimilatória líquida e área foliar específica, em relação aos diferentes níveis de luminosidade testados (médias de 9,3 cm; 0,0082 $\mathrm{g} \mathrm{cm}^{-2} ; 0,0006 \mathrm{~g} \mathrm{~cm}^{-2} \mathrm{dia}^{-1}$; e 186,24 $\mathrm{g} \mathrm{cm}^{-2}$, respectivamente). As mudas de pau-ferro apresentaram melhor desempenho de crescimento quando cultivadas sob $50 \%$ de sombreamento.

PALAVRAS-CHAVE: Caesalpinia ferrea Mart. ex. Tul. var. leiostachya Benth; ecofisiologia vegetal; desenvolvimento vegetal.

tem levado a uma drástica redução na base genética de espécies nativas. Entretanto, nos últimos anos, tem aumentado o interesse pela propagação destas espécies, em razão da necessidade de recuperação de áreas degradadas e recomposição da paisagem. Para atenuar estes problemas ambientais, torna-se necessário o desenvolvimento de estudos de base

1. Trabalho recebido em ago./2012 e aceito para publicação em maio/2013 (nº registro: PAT 19571).

2. Universidade Federal da Grande Dourados (UFGD), Faculdade de Ciências Agrárias, Dourados, MS, Brasil. E-mails: nadialenhard@yahoo.com.br, silvana.scalon@ufgd.edu.br.

3. Universidade Federal de Mato Grosso do Sul (UFMS), Chapadão do Sul, MS, Brasil.E-mail: vespasiano.neto@ufms.br. 4. Universidade Federal de Lavras (UFLa), Departamento de Biologia, Lavras, MG, Brasil. E-mail: amuriaa@ufla.br. 
fisiológica, sobretudo no que diz respeito à germinação de sementes, crescimento inicial de plantas e produção de mudas, no sentido de oferecer suporte a programas de recomposição destes ambientes degradados (Almeida et al. 2004).

Apesar de fatores ambientais abióticos não serem forças isoladas que atuam sobre as plantas, a radiação é fundamental como fonte essencial e direta de energia, para o desenvolvimento de todos os vegetais. Além da radiação, a temperatura, a água e as condições edáficas também são fatores importantes no desenvolvimento inicial das plantas (Aguiar \& Barbedo 1996, Almeida et al. 2004, Lima Júnior et al. 2006).

A luz está diretamente ligada à fotossíntese e sua intensidade e quantidade podem alterar o metabolismo e crescimento das plântulas (Marcos Filho 2005). A demora, em relação à emergência das plântulas, eleva o custo da produção de mudas. Pode-se avaliar a magnitude da necessidade de luz de uma espécie por meio de sombreamento artificial, no viveiro, o que confere uniformidade de iluminação e permite isolar e quantificar o efeito da luz (Portela et al. 2001).

O uso de telas para simulação de sombreamento tem sido adotado por diversos autores, em estudos de determinação das exigências luminosas, pelas mais diferentes espécies, na fase inicial de desenvolvimento. Dentre as espécies estudadas, muitas demonstram pouca exigência, quanto ao fator luz, apresentando desenvolvimento satisfatório a pleno sol ou sob sombreamento, como o guapuruvu (Schizolobium parahyba) (Caron et al. 2010) e o jatobá-do-cerrado (Hymenaea stigonocarpa) (Costa et al. 2011). Diferentemente, outras espécies apresentam preferência quanto à disponibilidade luminosa $\mathrm{e}$ desenvolvimento inicial maior em ambiente a pleno sol, como o paratudo (Tabebuia aurea) (Oliveira \& Perez 2012). Já o baru (Dipteryx alata) foi classificado, por Mota et al. (2012), como a espécie com melhor desenvolvimento inicial, quando cultivada em ambiente com 50\% de sombreamento.

Caesalpinia ferrea Mart. ex. Tul. var. leiostachya Benth, popularmente conhecida como pau-ferro, é uma espécie ecologicamente classificada como secundária inicial, que apresenta boa regeneração na floresta. É uma árvore que chega a atingir 10,0-20,0 $\mathrm{m}$ de altura, com tronco liso e escuro e manchas brancas irregulares, sendo muito utilizada para a arborização de parques e praças. Seus frutos são legumes de coloração preta-avermelhada, carnosos e indeiscentes (Lorenzi 2000), e sua casca, sementes, frutos e raízes são utilizados na medicina popular para emagrecimento, como depurativo e no combate à anemia, afecções pulmonares e diabetes (Braga 1976). As sementes de pau-ferro apresentam dormência física, sendo necessários tratamentos de escarificação, para a obtenção de germinação satisfatória acima de 70\% (Biruel et al. 2007). Para o desenvolvimento inicial das mudas, Lenhard et al. (2010) afirmam que o melhor regime hídrico é de $70 \%$ da capacidade de campo. Entretanto, a literatura é carente, no que diz respeito a informações sobre as respostas da espécie a diferentes condições de radiação.

Diante do exposto, e considerando-se que a utilização de espécies nativas em programas de conservação, proteção e recuperação de áreas requer informações de estádios de sucessão para o sucesso no plantio das mudas, este trabalho objetivou verificar as exigências de luminosidade, no crescimento inicial de mudas de pau-ferro.

\section{MATERIAL E MÉTODOS}

o experimento foi realizado de dezembro de 2006 a junho de 2007, sob condições de viveiro, no campus da Universidade Federal da Grande Dourados (UFGD), em Dourados (MS) (22 13'16"S, $54^{\circ} 17^{\prime} 01^{\prime \prime} \mathrm{W}$ e altitude de $430 \mathrm{~m}$ ). O clima desta localidade é classificado como Cwa (Mato Grosso do Sul 1990), sendo a precipitação e a temperatura média anual de $1.500 \mathrm{~mm} \mathrm{e} 22^{\circ} \mathrm{C}$, respectivamente.

Para o presente estudo, os frutos foram coletados em matrizes localizadas na área urbana do município de Dourados (MS) e beneficiados manualmente, no Laboratório de Fisiologia Vegetal da UFGD. Posteriormente, as sementes foram acondicionadas em embalagens de papel Kraft, em ambiente de laboratório, por 90 dias. Na pré-semeadura, as sementes foram escarificadas com ácido sulfúrico concentrado, por 15 minutos, para quebra de dormência tegumentar, e lavadas em água corrente, durante 10 minutos.

A semeadura foi realizada em bandejas de polietileno contendo substrato comercial (Plantmax ${ }^{\circledR}$ ), dispostas em bancadas sob condições de viveiro, com $50 \%$ de sombreamento, e as mudas irrigadas diariamente, até atingirem altura de $10,0 \mathrm{~cm}$, quando, então, foram transplantadas para embalagens de po- 
lietileno preto ( $18 \mathrm{~cm}$ x $30 \mathrm{~cm}$ ), com capacidade para $3,0 \mathrm{dm}^{3}$, contendo substrato constituído por $96,5 \%$ de solo de Cerrado (Latossolo Vermelho distroférrico) + $3,2 \%$ de cama de aviário $+0,3 \%$ de adubo químico Yoorim $^{\circledR}$.

As doses de $\mathrm{N}, \mathrm{P}_{2} \mathrm{O}_{5}, \mathrm{~K}_{2} \mathrm{O}$ e $\mathrm{S}$ aplicadas foram modificadas, com ampliação das doses de N, P, K e $S$ recomendadas por Barros \& Novais (1999), para a elaboração de substrato a ser utilizado na produção de mudas de eucalipto, após análise do solo.

O Yoorim ${ }^{\circledR}$ apresenta, em sua composição, $17,5 \%$ de $\mathrm{P}_{2} \mathrm{O}_{5}$ total; $16 \%$ de $\mathrm{P}_{2} \mathrm{O}_{5}$ solúvel em ácido cítrico a $2 \%(1: 100) ; 20 \%$ de Ca; $7 \%$ de $\mathrm{Mg} ; 0,1 \%$ de B; $0,55 \%$ de $\mathrm{Zn} ; 0,12 \%$ de $\mathrm{Mn} ; 0,05$ de $\mathrm{Cu} ; 0,006 \%$ de $\mathrm{Mo} ; 28 \%$ de $\mathrm{CaO}$; e $14,5 \%$ de $\mathrm{MgO}$. Após o transplante, as mudas foram mantidas em viveiro, por 30 dias, para aclimatização, e, em seguida, transferidas para os tratamentos com 70\%, 50\% e 0\% (pleno sol) de sombreamento. Os níveis de sombreamento foram obtidos por meio de telas de poliolefina de cor preta.

As avaliações foram realizadas a cada 30 dias, sendo a primeira aos 60 dias após o transplante (DAT) e a última aos 180 DAT, e o delineamento experimental utilizado foi inteiramente casualizado, em esquema fatorial $3 \times 5$ (três níveis de sombreamento $\mathrm{x}$ cinco épocas de avaliação), com 4 repetições de 10 mudas.

Aos 60 DAT, foram avaliados a altura do caule $(\mathrm{cm})$ e o comprimento da maior raiz $(\mathrm{mm})$, utilizando-se régua graduada; diâmetro de colo (mm), com paquímetro digital, e teor de clorofila total $\left(\mu \mathrm{g} \mathrm{cm}^{2}\right)$, utilizando-se clorofilômetro SPAD 503; massa seca (g) de raízes (MSR), folhas (MSF) e parte aérea (MSPA); relação raiz/parte aérea (R/PA); área foliar $(\mathrm{AF})\left(\mathrm{cm}^{2}\right)$, medida por meio de um integrador de área foliar LICOR 3000; razão de peso foliar (RPF) $\left(\mathrm{g} \mathrm{g}^{-1}\right)$; peso específico de folha (PEF) $\left(\mathrm{g} \mathrm{cm}^{-2}\right)$; razão de área foliar (RAF) $\left(\mathrm{cm}^{2} \mathrm{~g}^{-1}\right)$; área foliar específica (AFE) $\left(\mathrm{cm}^{2} \mathrm{~g}^{-1}\right)$; taxa assimilatória líquida (TAL) $\left(\mathrm{g} \mathrm{cm}^{-2} \mathrm{dia}^{-1}\right)$; e taxa de crescimento relativo (TCR) $\left(\mathrm{g} \mathrm{g}^{-1} \mathrm{dia}^{-1}\right)$ (Benincasa 1988).

Os resultados foram submetidos à análise de variância e, havendo diferenças significativas entre os dados, as médias foram comparadas pelo teste Tukey, a 5\%. As médias dos períodos de avaliação foram ajustadas por meio de equações de regressão, utilizando-se o programa estatístico Sanest.

\section{RESULTADOS E DISCUSSÃO}

As mudas de pau-ferro apresentaram variações no crescimento, influenciadas pelo nível de sombreamento fornecido. A maior altura das plantas ocorreu sob 50\% de sombreamento, aos 180 DAT, enquanto, a pleno sol, as plantas apresentaram menor porte (Figura 1a). Estes resultados estão de acordo com a classificação da espécie, por Carvalho (2003), como secundária inicial.

Em estudos realizados com jatobá (Hymenaea courbaril), fedegoso (Senna macranthera) e moreira (Maclura tinctoria), sob $0 \%, 30 \%$ e $50 \%$ de sombreamento, Almeida et al. (2005) verificaram maiores alturas sob 50\% de interceptação da radiação solar. Lima et al. (2007), em estudo com andiroba (Virola surinamensis), e Mota et al. (2012), com baru (Dipteryx alata), verificaram maiores alturas de plantas sob $50 \%$ de sombreamento. No entanto, algumas espécies, como Machaerium sp. (Batiston et (a)

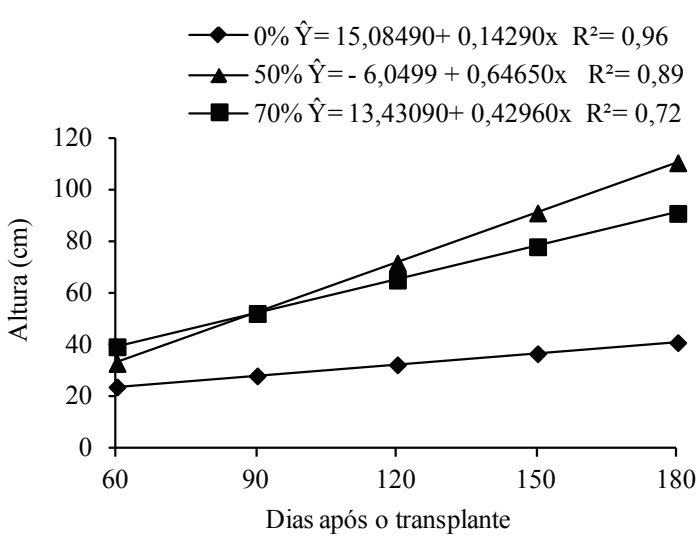

(b)

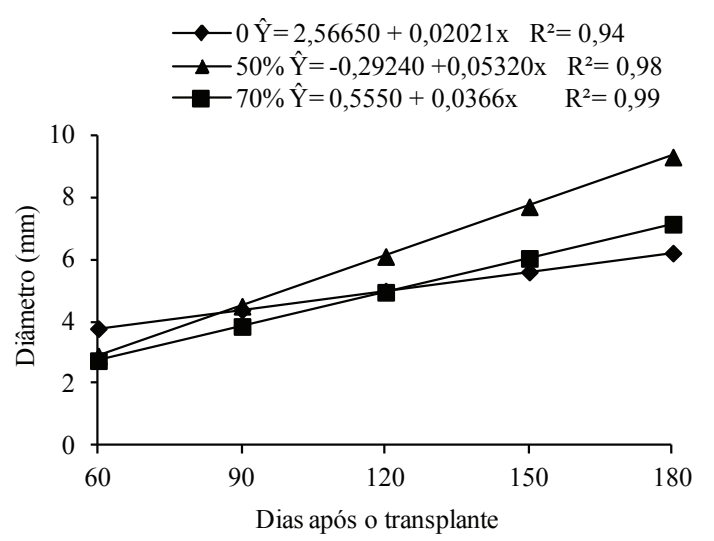

Figura 1. Altura (a) e diâmetro de colo (b) das mudas de Caesalpinia ferrea, em função do tempo e níveis de sombreamento (Dourados, MS, 2007). 
al. 2008) e Tabebuia aurea (Oliveira \& Perez 2012), apresentaram maior plasticidade, para este parâmetro, sem variação no porte das plantas, sob diferentes níveis de sombreamento.

A adaptação a baixas irradiâncias é uma característica genética que faz com que as folhas apresentem estrutura anatômica e propriedades fisiológicas que as capacitem à utilização efetiva da radiação solar disponível (Larcher 2000). A redução do crescimento em altura a pleno sol pode estar relacionada à elevação da temperatura nas folhas e, desta forma, à intensificação na taxa respiratória, que, indiretamente, pode induzir o fechamento dos estômatos, com consequente redução da fixação de carbono, causando, ainda, aumento no consumo de fotoassimilados (Kozlowski et al. 1991).

O sombreamento induziu aumento no diâmetro de colo das mudas, apresentando diferença significativa entre os tratamentos. Entretanto, esta diferença foi maior para as mudas cultivadas sob 50\% de sombreamento (Figura 1b), quando comparadas com as cultivadas sob $0 \%$ e $70 \%$ de sombreamento, reforçando o fato de a espécie ser classificada como secundária inicial. Resultados semelhantes foram observados para canela-batalha (Cryptocaria aschersoniama) (Almeida et al. 2004) e jatobá (H. courbaril) (Almeida et al. 2005). Por outro lado, Batiston et al. (2008) observaram comportamento diferente para Machaerium sp., a qual não apresentou variação no diâmetro de colo, quando submetida a diferentes níveis de sombreamento.

O crescimento da raiz, em comprimento, apresentou resposta linear, em função da idade das plantas, entretanto, não foi observada diferença

(a)

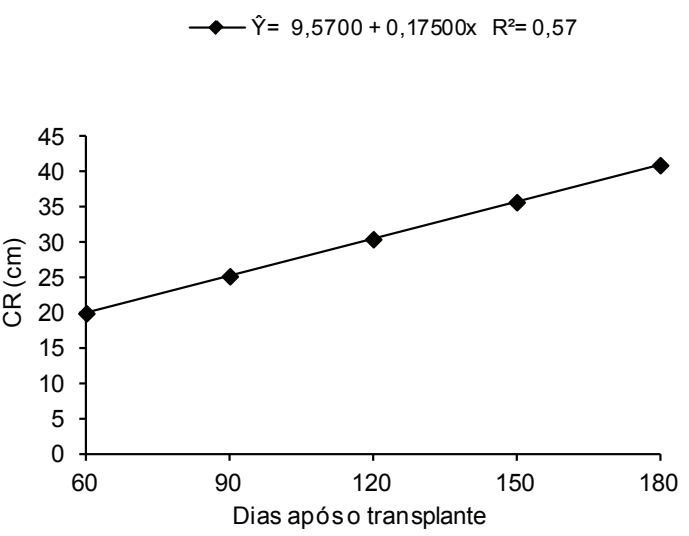

significativa, para esta característica, entre os níveis de sombreamento a que estas foram submetidas (Figura 2a).

No que diz respeito à massa seca das raízes, as mudas cultivadas sob $50 \%$ de sombreamento acumularam mais biomassa (média de 11,13 g), diferindo, significativamente, das plantas mantidas sob $70 \%$ e $0 \%$ de sombreamento, as quais apresentaram, respectivamente, em média, 5,2 g e 4,3 g de massa seca em seu sistema radicular, aos 180 dias após o transplantio das mudas (Figura 2b). Fato semelhante foi observado em plantas de óleo copaíba (Copaifera langsdorffii) (Salgado et al. 2001) e andiroba (V. surinamensis) (Lima et al. 2007), que, também, apresentaram melhor desempenho sob condições de sombreamento.

O investimento no sistema radicular é uma característica interessante de espécies adaptadas às condições do Cerrado, uma vez que a disponibilidade de água em solos deste bioma poderia ser um fator crítico. O Cerrado é, muitas vezes, caracterizado como uma "floresta invertida" (Abdala et al. 1998), em que a biomassa subterrânea é maior do que a biomassa aérea. Este padrão de desenvolvimento pode ser observado em outras plantas de savana, ao redor do mundo, e a captação de água e nutrientes é a principal explicação (Cairns et al. 1997).

A massa seca foliar (Figura 3a) apresentou resposta de crescimento linear, nas plantas sob 50\% e $70 \%$ de sombreamento. Para as plantas a pleno sol, não houve ajuste aos modelos testados, no entanto, as mesmas apresentaram valores inferiores aos das plantas sombreadas. Resultados semelhantes foram observados para velame (Sclerolobium paniculatum)

(b)

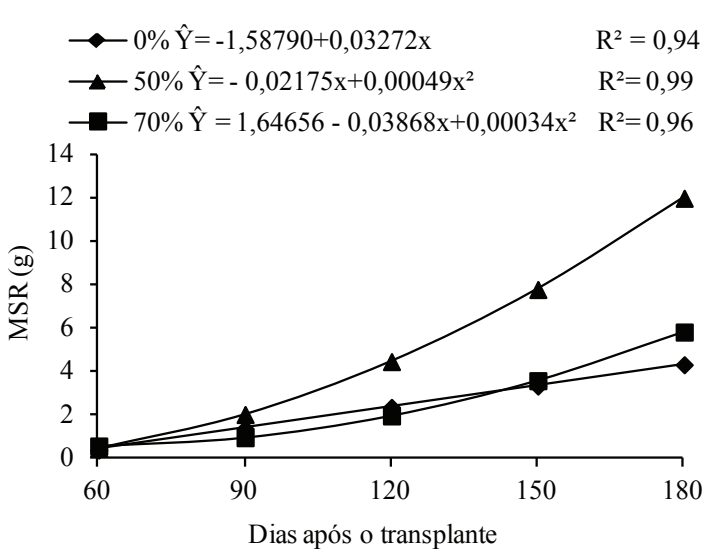

Figura 2. Comprimento da raiz (a) e massa seca da raiz (b) das mudas de Caesalpinia ferrea, em função do tempo e níveis de sombreamento (Dourados, MS, 2007). 
(a)

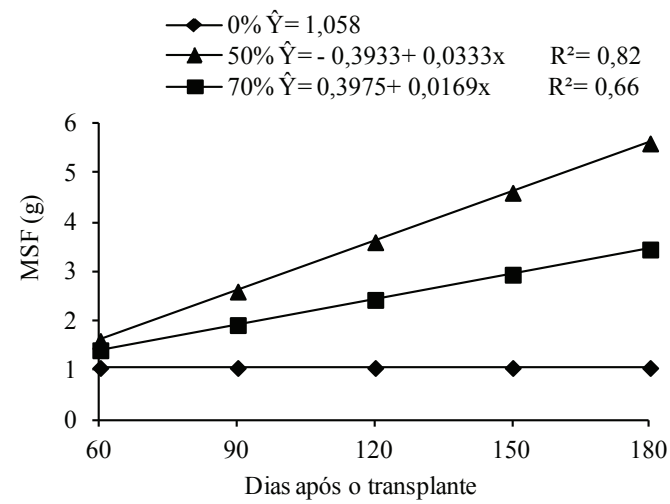

(b)

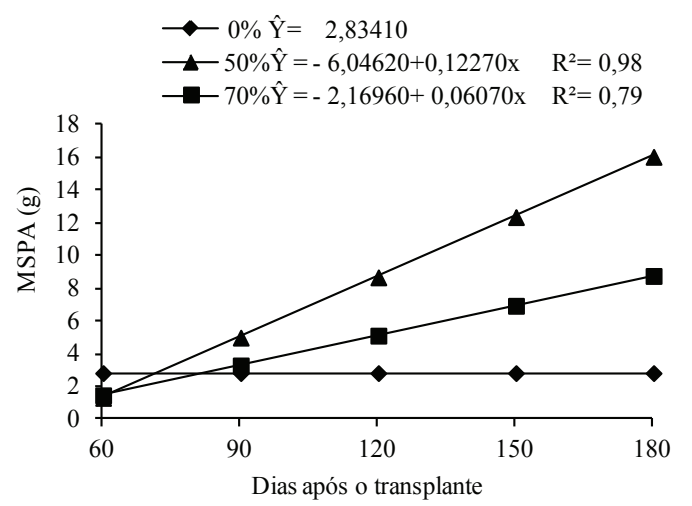

Figura 3. Massa seca da folha (a) e massa seca da parte aérea (b) das mudas de Caesalpinia ferrea, em função do tempo e níveis de sombreamento (Dourados, MS, 2007).

(Felfili et al. 1999) e andiroba (V. surinamesis) (Lima et al. 2007), que alocaram maior quantidade de biomassa para as folhas, quando cultivadas sob $50 \%$ de sombreamento.

Mudas de Euterpe edulis apresentaram intolerância à plena luz, com redução da massa seca (Nakazono et al. 2001). A exposição prolongada das plantas à alta irradiância pode ser prejudicial, devido à fotoinibição do aparelho fotossintetizante, com reduções significativas na fotossíntese, podendo levá-las, inclusive, à morte (Kitao 2000). Por outro lado, algumas espécies, como o jequitibá-rosa (Cariniana legalis) e cumaru-de-cheiro (Amburana cearensis), estudadas por Rego \& Possamai (2006) e Ramos et al. (2004), respectivamente, mostraram melhores desempenhos quando crescidas sob luz plena, acumulando mais biomassa nas folhas.

Mudas de pau-ferro cultivadas sob $50 \%$ e $70 \%$ de sombreamento alocaram maiores quanti-

(a)

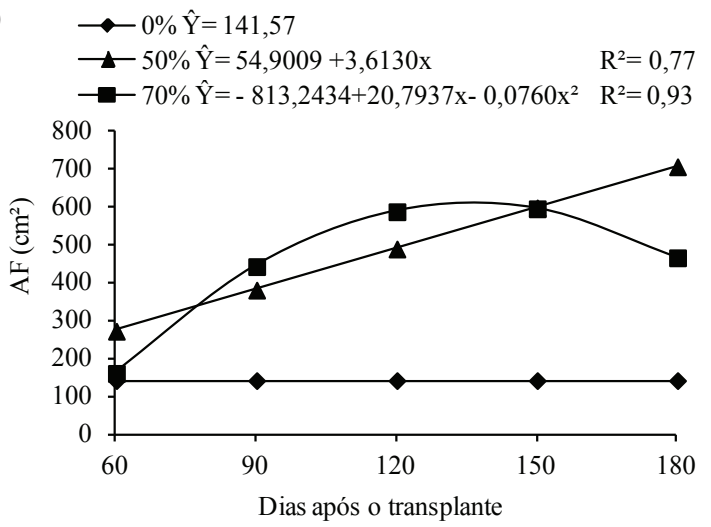

dades de massa seca para a parte aérea (Figura 3b). Estes resultados corroboram os encontrados para Sclerolobium paniculatum (Felfili et al. 1999), H. courbaril (Mazzei et al. 1999), Maclura tinctoria (Almeida et al. 2005) e V. Surinamensis (Lima et al. 2007), comumente conhecidas como velame, jatobá, moreira e andiroba, respectivamente.

Com relação à área foliar, as mudas apresentaram resposta diferencial ao crescimento (Figura 4a), indicando que esta característica é determinada pela condição ambiente a que a planta está submetida.

$\mathrm{O}$ aumento em área foliar, com o sombreamento, é uma das adaptações que permite às plantas investirem sua biomassa no crescimento da superfície fotossintetizante, assegurando maior aproveitamento de baixas intensidades luminosas (Pedroso \& Varela 1995).

A maior área foliar foi encontrada nas plantas crescidas sob 50\% de sombreamento, aos 180 DAT.

(b)

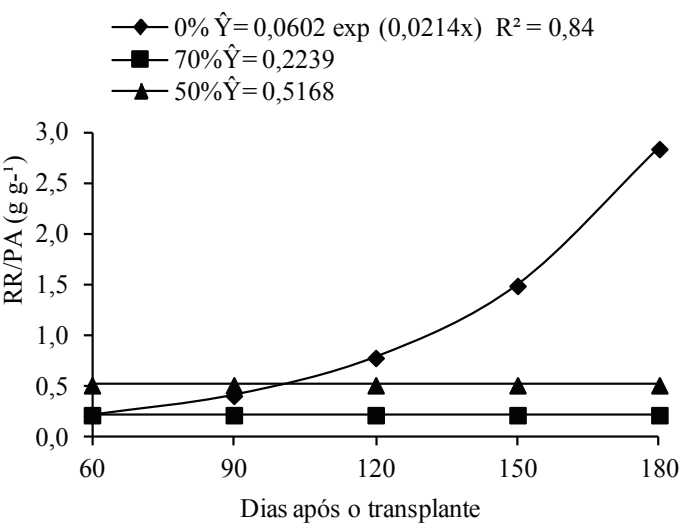

Figura 4. Área foliar (a) e relação raiz/parte aérea (b) das mudas de Caesalpinia ferrea, em função do tempo e níveis de sombreamento (Dourados, MS, 2007). 
O crescimento da área foliar foi sensivelmente prejudicado pela exposição a pleno sol, sendo a média de $141,57 \mathrm{~cm}^{2}$ a menor, dentre os tratamentos testados. Resultados semelhantes foram encontrados por Lima et al. (2007), em que andiroba (V. surinamensis) crescida sob $50 \%$ de sombreamento apresentou maior área foliar do que quando cultivada a pleno sol. Tambelini \& Perez (2007) também corroboram os resultados de maior área foliar, em três espécies de Cerrado cultivadas sob ambiente sombreado. Diferentemente, Machaerium sp. apresentou maior área foliar a pleno sol, em comparação a plantas cultivadas sob regimes de sombreamento.

Ao contrário do que ocorreu nos tratamentos com $0 \%$ e $70 \%$ de sombreamento, a maior produção de massa seca das folhas, raiz e parte aérea das mudas de pau-ferro ocorreu sob 50\% de sombreamento, indicando que esta intensidade luminosa favoreceu a produção de fotoassimilados. Adversamente, as condições propiciadas pelos tratamentos sob $70 \%$ de sombreamento e pleno sol estabeleceram condições insuficientes para suprir a demanda de crescimento da planta, pela baixa e excessiva intensidades luminosas, respectivamente, resultando em baixa produção de fotoassimilados.

Por outro lado, as mudas cultivadas a pleno sol apresentaram maior relação raiz/parte aérea, em comparação aos demais tratamentos (Figura 4b), evidenciando que, sob estas condições, as plantas necessitam de um sistema radicular mais desenvolvido para suprir, eventualmente, as demandas transpiratórias. Resultados semelhantes foram verificados para S. paniculatum Vog. var. rubiginosum (Tul.) Benth. (Felfili et al. 1999) e caroba [Jacaranda copaia (Aubl.) D. Don] (Campos \& Uchida 2002)

(a)

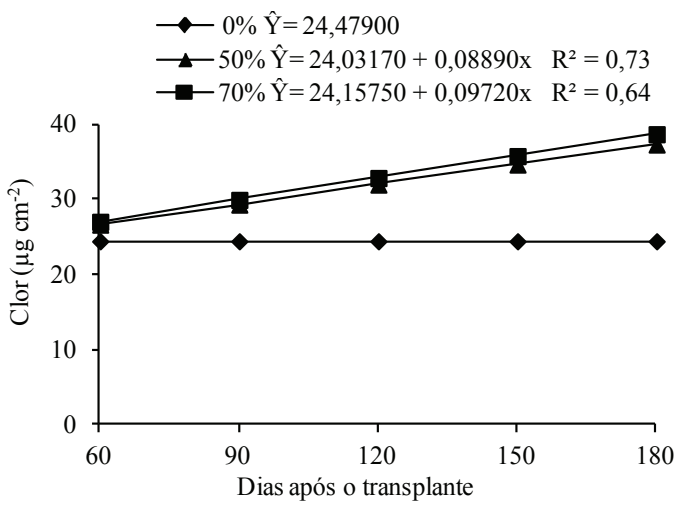

submetidas a diferentes níveis de sombreamento, para as quais os melhores resultados foram verificados a pleno sol.

Segundo Fonseca et al. (2002), em condições de pleno sol, a taxa de evaporação do solo é maior, o que torna a água menos disponível para o sistema radicular, levando, assim, a um maior crescimento das raízes, enquanto, sob sombreamento, a temperatura do ambiente ao redor das mudas pode diminuir em até $5^{\circ} \mathrm{C}$, o que, provavelmente, reduz a taxa de evaporação e mantém a umidade do solo por maior tempo.

No que diz respeito aos teores de clorofila, as plantas apresentaram maiores valores sob $70 \%$ e $50 \%$ de sombreamento (Figura 5a). Resultados semelhantes foram observados em plantas jovens de camboatã (Cupania vernalis), para as quais os maiores valores de clorofila foram observados em plantas submetidas a $50 \%$ e $70 \%$ de sombreamento, em comparação com as mudas crescidas sob 30\% de sombreamento e a pleno sol (Lima Júnior et al. 2006). Adicionalmente, Rego \& Possamai (2006), trabalhando com jequitibá-rosa (C. legalis) submetido a 100\%, 70\%, 64\%, 44\% e $34 \%$ de luminosidade, também observaram que os níveis de sombreamento mais elevados proporcionaram maiores teores de clorofila.

O maior acúmulo de clorofila em ambientes mais sombreados pode ser devido a um efeito compensatório da espécie, quando encontra-se em ambiente onde ocorre menor radiação solar (Naves et al. 1994). Esta ideia é reforçada por Boardman (1977), ao sugerir que folhas cultivadas sob baixas intensidades de luz apresentam maiores teores de clorofila por unidade de peso, e que folhas de sombra apresentam maior concentração de clorofila, quando

(b)

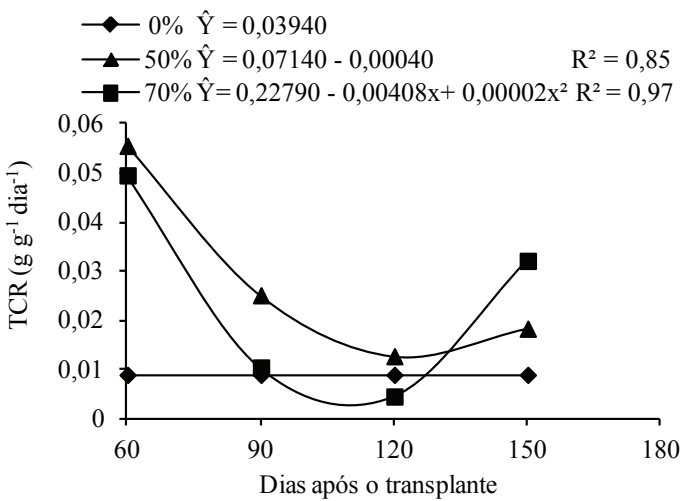

Figura 5. Teor de clorofila (a) e taxa de crescimento relativo (b) das mudas de Caesalpinia ferrea, em função do tempo e níveis de sombreamento (Dourados, MS, 2007). 
comparadas às de sol. Ainda segundo este autor, uma possível justificativa para este comportamento é que as plantas crescidas sob baixas radiações apresentam melhor desenvolvimento de grana.

Em plantas cultivadas a pleno sol, a taxa de crescimento relativo manteve-se baixa e constante, até os 150 DAT, enquanto, sob $70 \%$ e $50 \%$ de sombreamento, observou-se queda substancial, no período compreendido entre 60 DAT e 120 DAT, recuperando-se, em seguida (Figura 5b). Isto demonstra que a diminuição na disponibilidade de luz teve efeito positivo na taxa de acúmulo da matéria seca das plantas (Tabela 1). Resultados semelhantes também foram observados em plantas de andiroba (V. surinamensis) sob 50\% de sombreamento e a pleno sol, em que as plantas sob $50 \%$ de sombreamento apresentaram maior taxa de crescimento relativo (TCR) (Lima et al. 2007).

A razão de área foliar (relação entre a área foliar e a correspondente massa seca total) das plantas mantidas sob $70 \%$ de sombreamento apresentou valores mais elevados que os dos demais tratamentos (Tabela 1). Resultados semelhantes foram verificados em mudas de sumaúma (Ceiba pentandra) cultivadas a pleno sol e sob $30 \%, 50 \%$ e $70 \%$ de sombreamento (Pedroso \& Varela 1995), com as plantas sob $70 \%$ e $50 \%$ de sombreamento apresentando maior razão de área foliar (RAF). Duz et al. (2004), estudando embaúva-vermelha (Bathysa australis), embaúba (Cecropia glaziovi) e cedro (Cedrela fissilis) sob 2\%, 15\%, 30\% e 50\% de luminosidade, verificaram decréscimo na RAF, com o aumento da radiação solar.

Em relação à razão de peso foliar (RPF), os maiores valores foram observados nas plantas crescidas sob $70 \%$ e $50 \%$ de sombreamento e o menor valor a pleno sol (Tabela 1). Sob condições de som-

Tabela 1. Razão de área foliar (RAF), razão de peso foliar (RPF) e taxa de crescimento relativo (TCR) das mudas de Caesalpinia ferrea sob $0 \%, 50 \%$ e $70 \%$ de sombreamento (Dourados, MS, 2007).

\begin{tabular}{lccc}
\hline \multirow{2}{*}{ Tratamentos } & RAF & RPF & TCR \\
\cline { 2 - 4 } & $\mathrm{cm}^{2} \mathrm{~g}^{-1}$ & $\mathrm{~g} \mathrm{~g}^{-1}$ & $\mathrm{~g} \mathrm{~g}^{-1} \mathrm{dia}^{-1}$ \\
\hline Pleno sol & $24,4701 \mathrm{c}$ & $0,1859 \mathrm{~b}$ & $0,0091 \mathrm{~b}$ \\
$50 \%$ & $39,2043 \mathrm{~b}$ & $0,2395 \mathrm{a}$ & $0,0279 \mathrm{a}$ \\
$70 \%$ & $51,5426 \mathrm{a}$ & $0,2708 \mathrm{a}$ & $0,0242 \mathrm{ab}$ \\
\hline CV $(\%)$ & 31,10 & 19,59 & 25,16 \\
\hline
\end{tabular}

Médias seguidas da mesma letra, na coluna, não diferem entre si, a $5 \%$, pelo teste Tukey. breamento parcial, as folhas tendem a apresentar área foliar maior e massa seca menor. Isto representa um artifício da planta, a fim de otimizar a interceptação luminosa (Benincasa 1988). Resultados semelhantes foram obtidos por Nakazono et al (2001), em pesquisa com Eucalyptus edulis sob 2\%, 6\% e 20\% de incidência solar, com plantas sob maior sombreamento exibindo maior RPF.

No que diz respeito aos índices de taxa assimilatória líquida (TAL), área foliar específica (AFE) e peso específico foliar (PEF) das mudas, não foram observadas diferenças entre níveis de sombreamento, cujos valores médios foram $0,0006 \mathrm{~g} \mathrm{~cm}^{-2} \mathrm{dia}^{-1}, 168,1951 \mathrm{~cm}^{2} \mathrm{~g}^{-1}$ e $0,0082 \mathrm{~g} \mathrm{~cm}^{-2}$, respectivamente.

Resultados semelhantes para a TAL foram observados por Scalon et al. (2003), em castanha do maranhão (Bombacopsis glabra) cultivada a pleno sol e sob $30 \%$ e $50 \%$ de sombreamento. Entretanto, observou-se ligeiro aumento no PEF das plantas crescidas sob $50 \%$ de luz, enquanto houve aumento na AFE das plantas sob $70 \%$ de sombreamento (dados não apresentados).

De acordo com Dale (1988), algumas plantas crescidas sob sombreamento apresentam mecanismos adaptativos, com aumento da área foliar para maximizar a captação da luz solar, dentre eles a diminuição do peso específico foliar, em detrimento de uma maior área foliar. Nakazono et al. (2001) também não verificaram diferença significativa no PEF, em E. edulis crescendo sob $20 \%, 30 \%, 50 \%$ e $70 \%$ de sombreamento, corroborando os resultados do presente estudo.

\section{CONCLUSÃO}

As mudas de Caesalpinia ferrea apresentaram melhores parâmetros fisiológicos de crescimento quando mantidas em ambiente sob $50 \%$ de sombreamento, culminando com maiores taxas de crescimento.

\section{AGRADECIMENTOS}

Ao Conselho Nacional de Desenvolvimento Científico e Tecnológico (CNPq), pela concessão de bolsa de estudos à primeira autora, e à Fundação de Apoio ao Desenvolvimento de Ensino, Ciência e Tecnologia do Mato Grosso do Sul (Fundect), pelo apoio financeiro. 


\section{REFERÊNCIAS}

ABDALA, G. C. et al. Above and below organic matter and root:shoot ratio in a Cerrado in Central Brazil. Brazilian Journal of Ecology, Rio Claro, v. 2, n. 1, p. 11-23, 1998.

AGUIAR, F. F. A.; BARBEDO, C. J. Efeito de fatores ambientais no crescimento de mudas de Pau-brasil (Caesalpinia echinata Lam.). Revista Brasileira de Horticultura Ornamental, Jaboticabal, v. 2, n. 1, p. 2632, 1996.

ALMEIDA, L. P. et al. Crescimento inicial de plantas de Cryptocaria aschersoniana Mez. submetidas a níveis de radiação solar. Ciência Rural, Santa Maria, v. 34, n. 1, p. 83-88, 2004.

ALMEIDA, S. M. Z. et al. Alterações morfológicas e alocação de biomassa em plantas jovens de espécies florestais sob diferentes condições de sombreamento. Ciência Rural, Santa Maria, v. 35, n. 1, p. 62-68, 2005.

BARROS, N. F.; NOVAIS, R. F. de. Eucalipto. In: RIBEIRO, A. C.; GUIMARÃES, P. T. G.; ALVAREZ, V. H. (Eds.). Recomendações para o uso de corretivos e fertilizantes em Minas Gerais: $5^{\mathrm{a}}$ aproximação. Viçosa: CFSEMG, 1999. p. 303-304.

BATISTON, D. A.; ARANTES, W. M.; ALMEIDA, V. P. Crescimento inicial de Machaerium sp. (LeguminosaePapilonoideae) em resposta a diferentes condições de sombreamento. Revista Eletrônica de Biologia, Sorocaba, v. 1, n. 3, p. 8-20, 2008.

BENINCASA, M. M. P. Análise de crescimento de plantas: noções básicas. Jaboticabal: FCVA-Unesp, 1988.

BIRUEL, R. P.; AGUIAR, I. B.; PAULA, R. C. Germinação de sementes de pau-ferro submetidas a diferentes condições de armazenamento, escarificação química, temperatura e luz. Revista Brasileira de Sementes, Londrina, v. 29, n. 3, p. 151-159, 2007.

BOARDMAN, N. K. Comparative photosynthesis of sun and shade plants. Annual Review of Plant Physiology and Plant Molecular Biology, Palo Alto, v. 28, n. 1, p. 355377, 1977.

BRAGA, R. Plantas medicinais do Nordeste, especialmente do Ceará. 3. ed. Mossoró: ESAM, 1976.

CAIRNS, M. A. et al. Root biomass allocation in the world's upland forests. Oecologia, Berlim, v. 111, n. 1, p. 1-11, 1997.

CAMPOS, M. A. S.; UCHIDA, T. Influência do sombreamento no crescimento de mudas de três espécies amazônicas. Pesquisa Agropecuária Brasileira, Brasília, DF, v. 37, n. 3, p. 281-288, 2002.
CARON, B. O. et al. Crescimento em viveiro de mudas de Schizolobium parahyba (Vell.) S. F. Blake. submetidas a níveis de sombreamento. Ciência Florestal, Santa Maria, v. 20, n. 4, p. 683-689, 2010.

CARVALHO, P. E. R. Espécies arbóreas brasileiras. Curitiba: Embrapa Florestas, 2003.

COSTA, E. et al. Desenvolvimento inicial de mudas de jatobazeiro do Cerrado em Aquidauana - MS. Revista Brasileira de Fruticultura, Jaboticabal, v. 33, n. 1, p. $215-$ 226, 2011.

DALE, J. E. The control of leaf expansion. Annual Review of Plant Physiology and Plant Molecular Biology, Palo Alto, v. 39, n. 1, p. 267-295, 1988.

DUZ, S. R. et al. Crescimento inicial de três espécies arbóreas da Floresta Atlântica em resposta à variação na quantidade de luz. Revista Brasileira de Botânica, São Paulo, v. 27, n. 3, p. 587-596, 2004.

FELFILI, J. M. et al. Comportamento de plântulas de Sclerolobium paniculatum Vog. var. rubiginosum (Tul.) Benth. sob diferentes níveis de sombreamento em viveiro. Revista Brasileira de Botânica, São Paulo, v. 22, n. 2, p. 297-301, 1999.

FERREIRA, J. N.; RIBEIRO, J. F. R.; GOMES, A. C. Germinação de sementes de Piptadenia gonoacantha Mart. sob inundação. Boletim do Herbário Ezechias Paulo Heringer, Brasília, DF, v. 5, n. 1, p. 95-104, 2000.

FONSECA, P. V.; VALERI, S. V.; MIGLIORANZA, E. Padrão de qualidade de mudas de Trema micrantha (L.) Blume, produzidas sob diferentes períodos de sombreamento. Revista Árvore, Viçosa, v. 26, n. 4, p. 515 $523,2002$.

KITAO, M. Susceptibility to photoinhibition of three deciduous broadleaf tree species with different successional traits raised under various light regimes. Plant, Cell and Environment, Malden, v. 23, n. 1, p. 81-89, 2000.

KOZLOWSKI, T. T.; KRAMER, P. J.; PALLARDY, S. G. The physiological ecology of woody plants. Academic Press: Massachusetts, 1991.

LARCHER, W. Ecofisiologia vegetal. São Carlos: Rima, 2000 .

LENHARD, N. R.; SCALON, S. P. Q.; NOVELINO, J. O. Crescimento inicial de mudas de pau-ferro (Caesalpinia férrea MART. ex Tul. var. leiostachya Benth.) sob diferentes regimes hídricos. Ciência e Agrotecnologia, Lavras, v. 34, n. 4, p. 870-877, 2010.

LIMA, J. D.; SILVA, B. M. S.; MORAES, W. S. Efeito da intensidade da luz no crescimento de mudas de Virola surinames (Rol.) Warb. Ciências Exatas e da Terra, Ciências Agrárias e Engenharias, Ponta Grossa, v. 13, n. 2, p. 39-45, 2007. 
LIMA JÚNIOR, E. C. et al. Aspectos fisioanatômicos de plantas jovens de Cupania vernalis Camb. submetidas a diferentes níveis de sombreamento. Revista Árvore, Viçosa, v. 30, n. 1, p. 33-41, 2006.

LORENZI, H. Árvores brasileiras: manual de identificação e cultivo de plantas arbóreas nativas do Brasil. Nova Odessa: Plantarum, 2000.

MARCOS FILHO, J. Fisiologia de sementes de plantas cultivadas. Piracicaba: FEALQ, 2005.

MATO GROSSO DO SUL. Secretaria de Planejamento e Coordenação Geral. Atlas multireferencial do Estado de Mato Grosso do Sul. Campo Grande: Fundação IBGE, 1990.

MAZZEI, L. J. et al. Crescimento de plântulas de Hymenaea coubaril L. var. stilbocarpa (Hayne) Lee e Lang. em viveiro. Boletim do Herbário Ezechias Paulo Heringer, Brasília, DF, v. 4, n. 1, p. 21-29, 1999.

MOTA, L. H. S.; SCALON, S. P. Q.; HEINZ, R. Sombreamento na emergência de plântulas e no crescimento inicial de Dipteryx alata Vog. Ciência Florestal, Santa Maria, v. 22, n. 3, p. 423-431, 2012.

NAKAZONO, E. M. et al. Crescimento inicial de Euterpe edulis Mart em diferentes regimes de luz. Revista Brasileira de Botânica, São Paulo, v. 24, n. 2, p. 173-179, 2001.

NAVES, V. L.; ALVARENGA, A. A. de; OLIVEIRA, L. E. M. de. Comportamento estomático de mudas de três espécies florestais submetidas a diferentes níveis de radiação fotossinteticamente ativa. Ciência e Prática, Lavras, v. 18, n. 4, p. 408-414, 1994.

OLIVEIRA, A. K. M.; PEREZ, S. C. J. G. A. e. Crescimento inicial de Tabebuia aurea sob três intensidades luminosas. Ciência Florestal, Santa Maria, v. 22, n. 2, p. 263-273, 2012.
PEDROSO, S. G.; VARELA, V. P. Efeito do sombreamento no crescimento de mudas de sumaúma. Revista Brasileira de Sementes, Brasília, DF, v. 17, n. 1, p. 47-51, 1995.

PORTELA, R. C. Q.; SILVA, I. L.; PIÑA-RODRIGUES, F. C. M. Crescimento inicial de mudas de Clitoria fairchildiana Howard e Peltophorum dubium (Sprenge) Taub em diferentes condições de sombreamento. Ciência Florestal, Santa Maria, v. 11, n. 2, p. 163-170, 2001.

RAMOS, K. M. O. et al. Desenvolvimento inicial e repartição de biomassa de Amburana cearensis (Allemao) A. C. Smith, em diferentes condições de sombreamento. Acta Botanica Brasilica, São Paulo, v. 18, n. 2, p. 351358, 2004.

REGO, G. M.; POSSAMAI, E. Efeito do sombreamento sobre o teor de clorofila e crescimento inicial do jequitibárosa. Boletim de Pesquisa Florestal, Colombo, v. 53, n. 2, p. 179-194, 2006.

SALGADO, M. A. S. et al. Crescimento e repartição de biomassa em plântulas de Copaifera langsdorffii Desf. submetidas a diferentes níveis de sombreamento em viveiro. Brasil Florestal, Brasília, DF, v. 70, n. 1, p. 1321, 2001.

SCALON, S. P. Q. et al. Crescimento inicial de mudas de Bombacopsis glabra (Pasq.) A. Robyns sob condição de sombreamento. Revista Arvore, Viçosa, v. 27, n. 6, p. 753-758, 2003.

TAMBELINI, M.; PEREZ, S. C. J. G. A. e. Produção de mudas de três espécies de Cerrado sob diferentes intensidades luminosas. Revista Brasileira de Biociências, Porto Alegre, v. 5, supl. 2, p. 879-881, 2007. 